\title{
O profissional de Educação Física e o meio ambiente: uma experiência de educação ambiental e a melhora da qualidade de vida dos moradores dos centros urbanos
}

\author{
Professional Physical Education and the environment: environmental \\ education experience and improve the quality of life \\ of residents of urban centers
}

\section{Profesional de la Educación Física y el medio ambiente: experiencia de la educación ambiental y la promoción de la calidad de vida de los habitantes de los centros urbanos}

\author{
Lucinéia Bernardes de Paula PEREIRA ${ }^{1}$ \\ Tiele Rodrigues da SILVA ${ }^{1}$ \\ Lucas Rissetti DELBIM ${ }^{2}$ \\ Marcelo Studart HUNGER ${ }^{3}$ \\ Sergio Fernando ZAVARIZE ${ }^{4}$ \\ Anderson MARTELLI \\ ${ }^{1}$ Graduação em Educação Física da Faculdade Mogiana do Estado de São Paulo, FMG - Mogi Guaçu - SP, Brasil \\ ${ }^{2}$ Mestre em Sustentabilidade e Qualidade de Vida-UNIFAE, \\ Docente do Curso de Educação Física da Faculdade Mogiana do Estado de São Paulo, FMG - Mogi Guaçu - SP, Brasil \\ ${ }^{3}$ Mestre em Performance Humana pela Universidade Metodista de Piracicaba, UNIMEP \\ Docente do Curso de Educação Física da Faculdade Mogiana do Estado de São Paulo, FMG - Mogi Guaçu - SP, Brasil \\ ${ }^{4}$ Doutor em Psicologia pela Pontifícia Universidade Católica de Campinas, PUC-Campinas, \\ Diretor Acadêmico na Faculdade Mogiana do Estado de São Paulo, FMG - Mogi Guaçu - SP, Brasil \\ ${ }^{5}$ Mestrando do Programa de Pós-Graduação em Ciências Biomédicas - Centro Universitário Hermínio Ometto, \\ FHO| Uniararas, Araras-SP, Brasil, \\ Pós Graduado em Laboratório Clínico (Patologia Clínica) - Faculdade de Ciências Médicas, UNICAMP \\ Docente do Curso de Graduação em Educação Física da Faculdade Mogiana do Estado de São Paulo, FMG - Mogi Guaçu - SP, Brasil
}

\section{Resumo}

Nos dias atuais, a preocupação com o meio ambiente está presente na vida de grande parte da população residente nos grandes centros urbanos. O educador físico diante de suas atribuições pode ser considerado um profissional na disseminação de informações que favoreçam a preservação e a responsabilidade compartilhada com o meio ambiente e a educação ambiental no combate de nossos paradigmas quando retratamos a arborização urbana. O presente trabalho descreve uma experiência de educação ambiental desenvolvida por profissionais de Educação Física e o favorecimento da arborização urbana no município de Mogi Guaçu-SP. Apesar da importância, o tema é pouco estudado, servindo como um elo participativo entre o educador físico e a preservação dessa vegetação. Essa vegetação quando bem planejada favorece inúmeros benefícios como controle da poluição do ar, conforto ambiental com redução da temperatura, equilíbrio da umidade no ar, convívio social e a prática de atividades físicas favorecendo a melhoria da qualidade de vida.

Descritores: Educação Física e Treinamento; Urbanização; Educação Ambiental.

\begin{abstract}
Currently, concern for the environment is present at much of the life of the population living in urban centers. The physical education teacher in front of their duties can be considered a professional in the dissemination of information to encourage the preservation and shared responsibility for the environment and environmental education in the fight of our paradigms when we portray urban trees. This paper describes an environmental education experience developed by professionals of Physical Education and favoring urban trees in the city of Mogi Guaçu-SP. Despite its importance, the topic is understudied, serving as a participatory link between the physical educator and preservation of the vegetation. This vegetation when well-planned can to bring numerous benefits such as control of air pollution, environmental comfort with reduced temperature, moisture balance in the air, social interaction and physical activity favoring the improvement of quality of life.
\end{abstract}

Descriptors: Physical Education and Training; Urbanization; Environmental Education.

\section{Resumen}

Actualmente las políticas públicas dirigidas a la población LGBTT (lesbianas, gays, bisexuales, transexuales y travesti) en Brasil son escasos y incompatibles. Sin embargo, hay que reconocer los avances en la implementación de estas políticas. A partir de un contexto histórico y cultural, este artículo aporta reflexiones a través de un relato de experiencia en la búsqueda de garantizar los derechos dirigidos a una mujer transexual privada de libertad que hace necessitado para hacer frente a la cuestión de uma forma inédita. El estudio fue realizado por la psicología extracurricular supervisada en una Unidad de prisión, con el apoyo de la Defensoria Pública municipal de que se trate. Las intervenciones se realizaron para el proceso de transexuales, lo que contribuye a respetar el nombre social, el cambio de nombre en el registro civil y el tratamiento hormonal. Descriptores: Educación y Entrenamiento Físico; Urbanización; Educación Ambiental. 


\section{INTRODUÇÃO}

Vivemos em um país onde o meio ambiente sofreu e vem sofrendo em consequência do alto grau de desenvolvimento urbano, seja ele através do desmatamento ou perca de suas riquezas naturais deixando assim, um local a mercê de uma recuperação física e social ${ }^{1}$.

Dentre os inúmeros aspectos ambientais, este trabalho retrata a arborização urbana que segundo Martelli e Barbosa $^{2}$ é preciso disseminar a conscientização da importância dessa vegetação e preservação do meio ambiente nas áreas urbanas visando à melhora da qualidade de vida da população residente nesses locais. A arborização, além do caráter estético, também é fundamental e essencial na qualidade de vida, contribuindo para melhoria da saúde, lazer e o favorecimento de vários outros segmentos sociais ${ }^{3}$.

À medida que o homem aumenta sua habilidade ele também ocupa um papel de intervir no meio ambiente, mesmo não sendo sua ideia, através desta intervenção há uma modificação desse meio e extração de recursos naturais para sua satisfação de necessidades ocasionando diversos conflitos no meio ambiente $e^{4,5}$. Como uma ferramenta de enfrentamento, retratamos a educação ambiental, que segundo Andrade e Santo ${ }^{6}$, é exercida visando à conscientização de adolescentes e alunos ao meio global e da questão ambiental para então criar e assumir responsabilidades sociais e se transformarem em multiplicadores de ideias e ações.

Gonçalves Neto et al. ${ }^{7}$ retrata que os profissionais de diferentes áreas devem trabalhar juntos, contribuindo para o entendimento de que lidar com a problemática ambiental não é somente dever daqueles que governam, mas de graduados em Geografia, História, Matemática, Biologia, Educação Física, entre outros. Este intercâmbio consiste de pessoas com formação em diferentes campos do conhecimento, utilizando diferentes conceitos, métodos e termos.

O contato e o trabalho do educador físico com o meio ambiente promovem sensações e oportunidades indescritíveis e com isso ele passará valores para aqueles que ali estão sendo capazes de promover e despertar a conscientização e a importância sobre aquele meio para a melhoria e qualidade de vida ${ }^{8}$.

A interação, conhecimento e a vivência do profissional no ambiente natural tem que ser vivida e sentida para ser passado com mais intensidade para aqueles praticantes e conhecedores das práticas esportivas como caminhadas, arborismo e várias outras relacionadas ao meio ambiente ${ }^{9}$.

Entre as várias maneiras de vivenciar o lazer, um novo campo de estudos e investigações vem merecendo a atenção de vários pesquisadores, entre eles, Marinho ${ }^{10}$ e Bétran ${ }^{11}$ retratam nesse novo campo à relação existente entre lazer e a participação humana nos espaços representados pela natureza. Nos dias atuais tem aumentado a procura por momentos em que a natureza seja precursora por fortes emoções, o fato de sair da rotina, vivenciar e interagir com outras pessoas junto às belezas inerentes à natureza.

Essas relações entre os seres humanos e o meio ambiente, há algum tempo já vêm sendo discutidas e despertando interesse crescente em várias áreas de pesquisa e, atualmente, têm sido foco de estudo na área da motricidade humana, ainda que de maneira sutil ${ }^{11,12}$. Bruhns ${ }^{13}$ evidencia a importância de reflexão sobre esta interação humana com o meio ambiente, apontando o compromisso com mudanças de atitudes e valores, os quais possam interferir positivamente nessa relação.

Há tempos, os paradigmas e preconceitos interferem na arborização urbana. A falta de conhecimento faz com que menos árvores sejam plantadas na área urbana ${ }^{14}$. De acordo com Silva ${ }^{15}$, nos planos de arborização urbana alguns critérios devem ser levados em consideração como a escolha das espécies, largura da calçada, clima, solo, unidade do local e outros equipamentos urbanos. Neste sentido, a conscientização é um dos principais fatores para mudança de atitude do ser humano perante o meio ambiente ${ }^{16}$.

A maior dificuldade de se planejar a arborização deve-se ao fato da rede elétrica estar presente na maior parte das calçadas, quando não tem rede elétrica o problema fica por conta das calçadas serem estreitas, não sendo possível que se plante um número desejado de árvores ${ }^{17}$. É essencial o uso correto das plantas para plantio na área urbana, pois o uso indevido de espécies poderá acarretar uma série de prejuízos tanto para o usuário ou empresas prestadoras de serviços.

Analisando o contexto escolar em todos os níveis no Brasil e no mundo, as diretrizes da Educação ambiental vêm buscando organizar processos pedagógicos em relação ao meio ambiente ${ }^{16}$. Segundo Dantas e Souza ${ }^{18}$, a arborização urbana vem merecendo uma atenção cada vez maior em função dos benefícios proporcionados na área urbana. Além das funções que afetam diretamente a vida do homem do ponto de vista ecológico, a arborização urbana é fundamental, pois através dela pode-se guardar a identidade biológica de uma região, preservação e cultivo de várias espécies vegetais que ocorrem em cada município ou região específica e também oferecem abrigo e alimentação à fauna, local de descanso e como um todo, protege o ecossistema em que esta inserida.

Para Raber e Rabelato ${ }^{19}$, a arborização é considerada um tema recente e de evolução lenta. A presença de vegetação arbórea urbana apresenta benefícios e problemas, sendo indispensável a sua contemplação no planejamento urbano. Esse assunto é muito importante e requer o envolvimento das administrações públicas e da comunidade, cada qual com seu papel. 
$\mathrm{Na}$ arborização urbana, há relatos na literatura ${ }^{20}$ que tais espaços proporcionam melhor qualidade e integração da comunidade ao meio, possibilitando a socialização em um local agradável seguro e acolhedor (Figura 1).

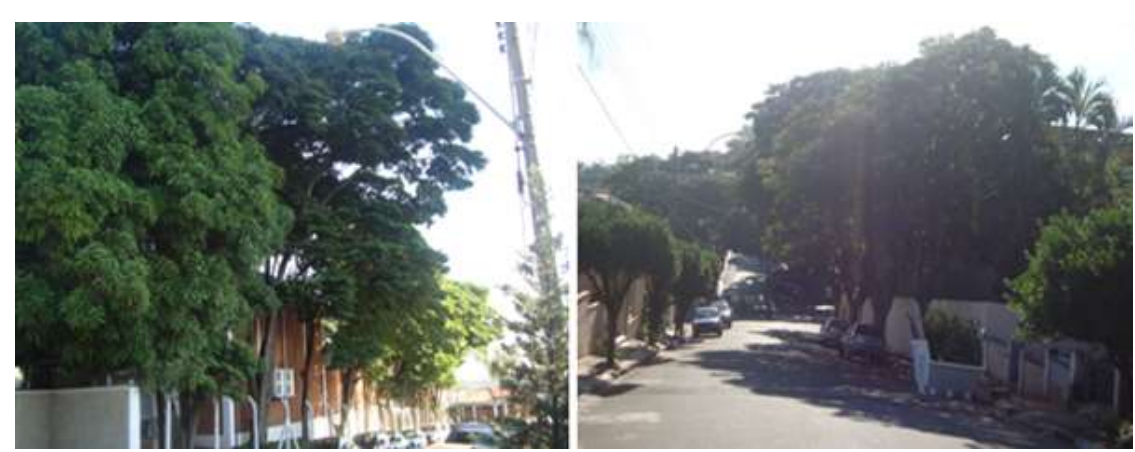

Figura 1. Arborização bem sucedida nas cidades.

Lado da via pública sem fio - arvores de grande porte e no lado com fiação - arvores de pequeno porte

As praças também configuram um local estratégico para o planejamento da arborização urbana, visto que são locais com menor confronto com as construções e com redes elétricas ${ }^{21}$. A arborização é essencial e contribui agindo sobre a parte física e mental do homem, atuando no sentimento de opressão frente às grandes edificações, ajuda na filtração do ar e de ruídos, exercendo uma ação de purificação e fixação de poeiras e resíduos tóxicos ${ }^{18}$.

Está muito bem descrito que a arborização urbana favorece uma melhor qualidade de vida para população, assim, esse trabalho apresenta como objetivo mostrar a importância da interação entre arborização urbana, educação ambiental e o profissional de Educação Física como disseminador dessas ações com a realização de palestra educativa, doação de sementes e plantio de árvores numa área pública junto aos estudantes e professores da Escola Municipal Emef Prof ${ }^{\mathrm{a}}$. Maria Lúcia Guillaumon Fonseca e uma maior divulgação sobre a importância do tema.

\section{MATERIAL E MÉTODO}

- CARACTERIZAÇÃO DO MUNICÍPIO DE MOGI GUAÇU Segundo o Portal de Mogi Guaçu ${ }^{22}$ o município é cortado pelo rio que originou seu nome, cujo significado na língua dos primeiros habitantes é "Rio Grande das Cobras". Com a chegada dos bandeirantes, que viajavam rumo ao oeste mineiro e a Goiás em busca do ouro, a população indígena foi diminuindo e, às margens do rio Mogi-Guaçu, foi formado um vilarejo para dar pouso aos desbravadores. Mogi Guaçu situa-se no interior do Estado de São Paulo, na Região Administrativa de Campinas, Região Fisiográfica de Pirassununga - 19a região, uma área de812 $163 \mathrm{Km}^{2}$, segundo censo do IBGE feito em 2010, o município possui 137.208 habitantes clima tipo CWO - inverno seco e verão chuvoso com precipitação de $1.162,7 \mathrm{~mm} / \mathrm{ano}^{23}$.

- PALESTRA EM SALA DE AULA

A ação ocorreu na sala de aula da Escola Municipal EMEF. Prof ${ }^{a}$. Maria Lúcia Guillaumon
Fonseca, com a realização de uma palestra sobre a importância da arborização urbana na melhoria da qualidade de vida da população residente nos centros urbanos para alunos do $3^{\circ}$ e $4^{\circ}$ ano letivo e professores.

Como forma de incentivar as propostas trabalhadas em sala de aula, ao final da palestra foram distribuídas sementes de árvores nativas acondicionadas em saquinhos e fixadas em cartões com as respectivas informações da espécie arbórea como: Família, nome científico, nome popular, características morfológicas e ocorrência nos biomas e por fim, as formas e procedimentos para a semeadura desta, Figura 2.

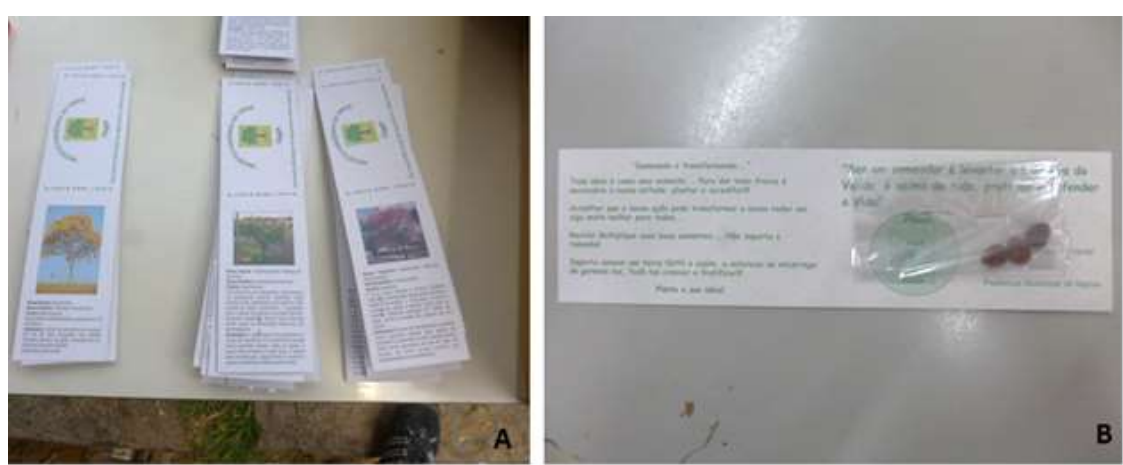

Figura 2. Em A, cartões explicativos com informações sobre a espécie arbórea e formas de semeadura, em B, acondicionamento da semente

\section{- PLANTIO EM ÁREA PÚBLICA}

Após a realização da palestra em sala, alunos e professores da respectiva escola deslocaram até uma área pública localizada na frente da unidade escolar para a realização de um plantio de 16 mudas de árvores nativas favorecendo a arborização urbana do município de Mogi Guaçu-SP.

Para o plantio, foi seguida a metodologia adotada por Martelli et al. $^{24}$, onde o preparo do terreno para plantio compreendeu com abertura das covas com dimensões de 30 centímetros de diâmetro por 50 centímetros de profundidade. O solo referente aos coveamentos foi misturado com aproximadamente $20 \%$ do volume da cova com adubo orgânico (esterco de curral). Um dia antes do plantio, foi realizada a separação das mudas no Viveiro Municipal vinculado a Prefeitura de Mogi Guaçu e no dia do evento, as mudas foram transportadas até o local de plantio e distribuídas próximas às covas abertas, combinando espécies dos diferentes estádios de sucessão e adaptadas às condições locais.

Com a chegada dos alunos e professores, foi realizada uma atividade de alongamento ao ar livre e as orientações pertinentes para a realização do plantio, assim como, enfatizando a importância da ação da arborização nos centros urbanos para a promoção da qualidade de vida e conforto térmico dos munícipes.

\section{RESULTADOS E DISCUSSÃO}

A palestra educativa foi realizada para aproximadamente 80 alunos do ensino fundamental $-3^{\circ}$ e $4^{\circ}$ ano enfatizando a importância da arborização em área urbana, sendo observado que o tema foi muito bem 
visto pelos alunos e professores, havendo uma participação ativa dos alunos com inúmeros questionamentos pertinentes sobre este tipo de vegetação, tempo de desenvolvimento, porte e suas funções (Figura 3).

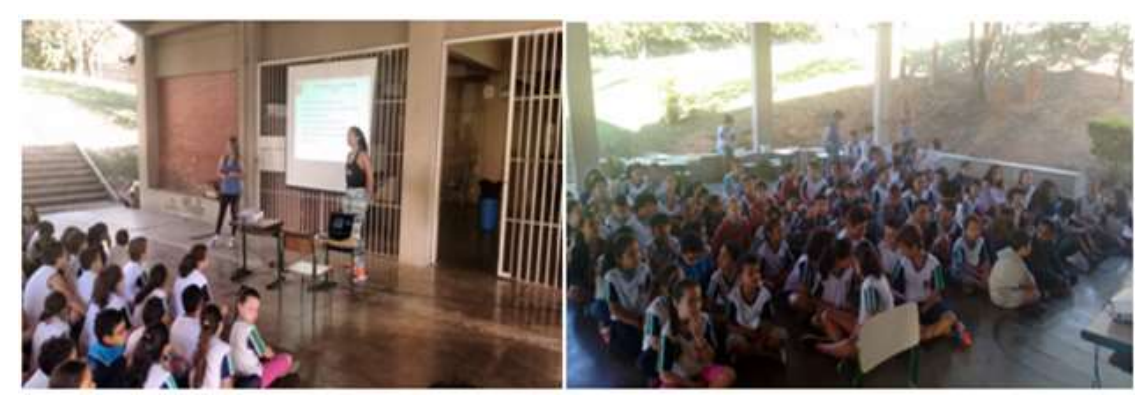

Figura 3. Palestra educativa sobre arborização urbana

Ribeiro $^{25}$ retrata que a arborização exerce função importante nos centros urbanos, sendo responsável por uma série de benefícios ambientais e sociais que melhoram a qualidade de vida nas cidades e a saúde física e mental da população.

Ao final da palestra e como forma de incentivar os alunos e professores na execução de ações favorecendo o aumento da arborização urbana, foi realizada a doação de sementes de arvores nativas, assim como, a descrição de toda a metodologia de semeadura e germinação das sementes, sendo observado um intenso interesse nas orientações prestadas quanto ao plantio destas e um comprometimento em cuidar das futuras mudas. Esse cuidado com a planta por parte da criança favorece a quebra de paradigmas em relação a esse tipo de vegetação. No total, foram doadas 300 sementes aos alunos e professores conforme demonstrado na Tabela 1, sendo das seguintes espécies: Ipê Roxo, Ipê Amarelo, Cássia Rosa e Flamboyanzinho.

Tabela 1. Valores relativos à doação de sementes

\begin{tabular}{l|l|l|l|l}
\hline Família & $\begin{array}{l}\text { Nome } \\
\text { Científico }\end{array}$ & Nome Popular & $\begin{array}{l}\text { Sementes } \\
\text { doadas }\end{array}$ & Freq. (\%) \\
\hline Bignoniaceae & $\begin{array}{l}\text { Tabebuia } \\
\text { heptaphylla }\end{array}$ & Ipê Roxo & 80 & 26,70 \\
\hline Bignoniaceae & $\begin{array}{l}\text { Tabebuia } \\
\text { chrysotricha }\end{array}$ & Ipê Amarelo & 80 & 26,70 \\
\hline Fabaceae & Cassia grandis & $\begin{array}{l}\text { Cássia Rosa/ Cássia } \\
\text { Grande }\end{array}$ & 72 & 24,0 \\
\hline Leguminosae. & $\begin{array}{l}\text { Caesalpinia } \\
\text { pulcherrima }\end{array}$ & $\begin{array}{l}\text { Flamboyanzinho/ } \\
\text { Flamboyant de Jardim }\end{array}$ & 68 & 22,60 \\
\hline Total & & & $\mathbf{3 0 0}$ & $\mathbf{1 0 0}$ \\
\hline
\end{tabular}

Dando continuidade as ações, os alunos e professores deslocaram em uma área pública e arborizada, Figura 4, localizada de frente à escola, onde foi realizado um exercício de alongamento, mostrando que o microclima proporcionado pela arborização favorece a prática de atividades físicas. Neste sentido, um estudo realizado em Lajedo-PE por Ferreira e Amador $^{26}$ com 225 pessoas foi observado que os entrevistados consideravam a arborização importante para os seres humanos e dentre os benefícios da arborização apontados, o fator sombra foi o que predominou na opinião dos moradores (56\%), seguido de redução de calor (20\%), redução da poluição sonora $(17,8 \%)$ e disponibilidade de flores e frutos $(6,2 \%)$. Os entrevistados também destacaram que a vegetação arbórea proporciona índices mais elevados de umidade do ar e ainda diminuem as concentrações de dióxido de carbono da atmosfera e reconheceram a importância da arborização para a melhoria da qualidade de vida nas cidades.

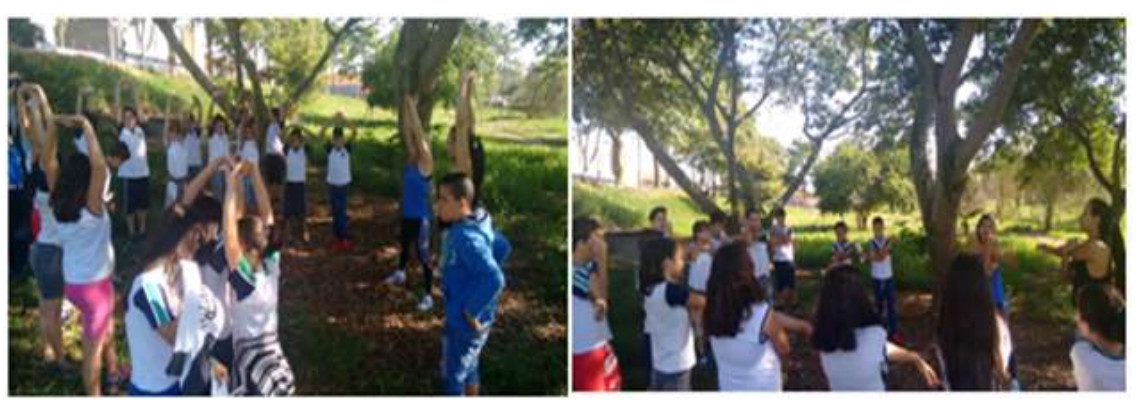

Figura 4. Prática de atividade física em uma área arborizada

Conforme evidencia Silva ${ }^{15}$, "do ponto de vista da área da Educação Física, algumas questões têm se mostrado de forma mais contundente [...] o lazer no contato com o meio natural, através dos denominados esportes radicais", demonstrando que as discussões sobre a natureza, no âmbito de tal área, têm se dado com maior ênfase às relacionadas ao lazer, ações humanas e à redescoberta do meio natural.

Nas discussões envolvendo o lazer, dificilmente o olhar do profissional de educação física tem se voltado à análise dos espaços onde esta atividade acontece, assim, discutir os espaços urbanos direcionados à prática do lazer esportivo, diante da carência teórica e conceitual na educação física no que tange ao debate sobre o espaço, requer uma aproximação com áreas do conhecimento na qual se tem poucas interfaces e afinidades ${ }^{27}$.

Para o plantio, realizado nas margens de córrego urbano sem denominação que passa por essa área verde, foram selecionadas um total de 16 mudas arbóreas nativas e bem adaptada ao clima local (Tabela 2).

Tabela 2. Relação das espécies arbóreas plantadas na área de estudo

\begin{tabular}{l|l|l|l}
\hline Nome Científico & Nome Popular & $\begin{array}{l}\text { Freq. } \\
\text { Absoluta }\end{array}$ & $\begin{array}{l}\text { Freq. } \\
\text { Relativa (\%) }\end{array}$ \\
\hline Morus nigra & Amora & 2 & 12,5 \\
\hline Malpighiae marginata & Acerola & 2 & 12,5 \\
\hline Psidium guajava & Goiaba & 2 & 12,5 \\
\hline Inga edulis & Ingá & 2 & 12,5 \\
\hline Cariniana estrellensis & Jequitibá Branco & 2 & 12,5 \\
\hline Eugenia uniflora & Pitanga & 2 & 12,5 \\
\hline Eugenia pyriformis & Uvaia & 2 & 12,5 \\
\hline Eugenia brasiliensis & Grumixama & 2 & 12,5 \\
\hline Total & & $\mathbf{1 6}$ & $\mathbf{1 0 0}$
\end{tabular}

Após as orientações pertinentes ao plantio e os benefícios da arborização, os alunos e professores engajados na ação, juntamente com a monitoria das técnicas, formaram grupos e percorreram os coveamentos realizando o plantio das espécies selecionadas (Figura 5).

Diante da ação e dos fatos observados, a educação ambiental é uma questão de atitude, onde os alunos poderão vivenciar e conscientizar para a preservação da 
natureza, promovendo atividades de caráter preventivo e defensivo do meio onde vivem ${ }^{7}$.

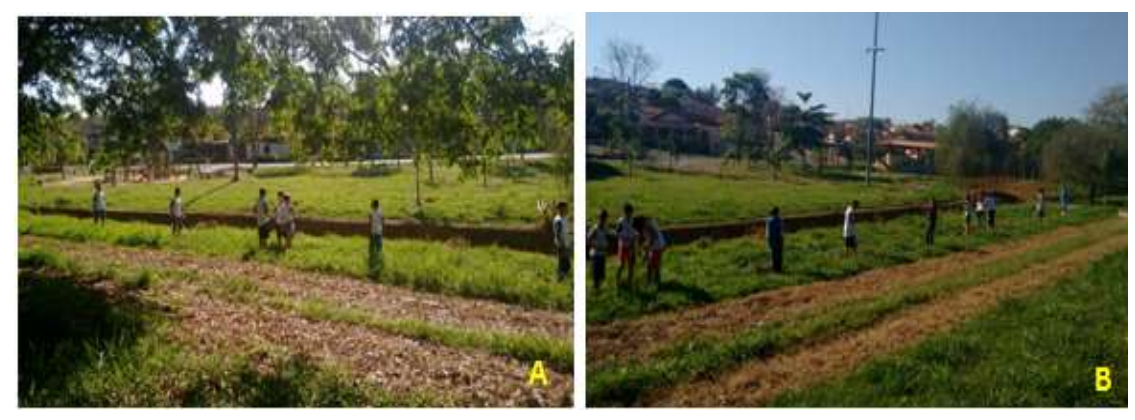

Figura 5. Reconstituição da arborização urbana na área verde, município de Mogi Guaçu/SP

Dentro deste conceito de Educação Ambiental, podemos trabalhar a arborização urbana, vegetação de extrema importância para uma sadia qualidade de vida, e sempre lembrando que cada cidadão reconheça e perceba sua influência no meio ambiente ${ }^{28}$. Fornecer cobertura arbórea é suficiente para garantir bem estar dos usuários que utilizam praças e lugares onde se pratica algum tipo de lazer, isso é essencial ${ }^{29}$.

Ferreira e Amador ${ }^{26}$ enfatizam que a percepção da população quanto aos benefícios trazidos por uma arborização adequada das áreas urbanas, tem sido utilizada em alguns bairros ou cidades do Brasil e a educação ambiental poderá ajudar as pessoas a perceberem mais o seu meio, conscientizando-se da necessidade de preservação. E neste contexto, o Educador Físico é parte importante neste processo ambiental, intermediando relação entre o homem e o meio, onde ambos interajam e contribua para o bem de $\operatorname{todos}^{7}$.

Apesar de existir um grande número de estudos que demonstrem a importância da arborização urbana na qualidade de vida e saúde das populações residentes nos centros urbanos com a amenização do clima, favorecimento da infiltração de agua no solo, à biodiversidade desse meio, é necessário o desenvolvimento de politicas públicas visando o aproveitamento das áreas sem vegetação e projetos bem orientados que intensifiquem o aumento dessa vegetação nos passeios públicos.

\section{CONSIDERAÇÕES FINAIS}

Diante do cenário ambiental que estamos passando fica evidente a importância de politicas públicas e planejamento do meio físico visando os elementos naturais encontrados na área urbana com as espécies vegetais. No decorrer do processo de expansão dos grandes centros urbanos é possível observar a devida falta de atenção às questões ambientais dentre elas o aumento e manutenção da arborização urbana visando a mitigação de inúmeros impactos ambientais negativos e o aumento da qualidade de vida da população residente.

Nas questões envolvendo arborização urbana é preciso planejar o plantio das árvores nesta área tomando como base os critérios técnicos adequados de forma a reduzir os danos materiais (muros e calçadas) para que haja, de fato, uma redução do numero de supressões arbóreas e que a população perceba os benefícios da arborização urbana visando à melhoria do ambiente urbano.

Os trabalhos desenvolvidos com o tema arborização urbana junto aos alunos e professores das escolas municipais e outros seguimentos da sociedade em geral favorecem a formação de cidadãos conscientes e aptos para decidirem e atuarem na realidade socioambiental com comprometimento visando o bem estar de cada um, da sociedade e da localidade onde vivem.

O entusiasmo visto na ação desenvolvida e o modo de pensar com criatividade e em conjunto em prol da promoção de mudanças nos conceitos ambientais é ponto de partida nas transformações dos jovens em relação ao meio ambiente que os cercam, e gerar cidadãos com um olhar ampliado e modificado para mundo, sendo esta, a condição básica para o alcance de uma melhor qualidade ambiental urbana e um padrão mínimo de qualidade de vida.

\section{REFERÊNCIAS}

1. Andrade J, Sanqueta CR, Ugaya C. Identificação de Áreas Prioritárias para Recuperação da Mata Ciliar na UHE Salto Caxias. Espaço Energia. 2005; (3).

2. Martelli A, Barbosa Junior J. Analise da incidência de supressão arbórea e suas principais causas no perímetro urbano do município de Itapira-SP. REVSBAU. 2010;5(4):95-108.

3. Müller J. Orientação básica para manejo da arborização urbana. Edições FAMURS. Porto Alegre: Nova Prova, 1998.

4. Martelli A, Santos Júnior AR. Arborização Urbana do município de Itapira - SP: perspectivas para educação ambiental e sua influência no conforto térmico. REGET/UFSM. 2015; 19(2)1018-31.

5. Martelli A. Educação ambiental: experiências e ações no aumento da arborização urbana do município de Itapira - SP Rev Faculdades do Saber. 2015;2(4):317-47.

6. Andrade KCM, Santo MEP. Arborização Como Prática da Educação Ambiental na Escola Lions de Parnamirim. In: JORNADA DE ENSINO, 2010; Recife. Recife: Jepex. Disponível em: http://www.sigeventos.com.br/jepex/inscricao/resum os/0001/R0153-1.PDF> 14 de fevereiro 2015.

7. Gonçalves Neto AJ, Catenassi FZ, Carvalho MAV. Educação ambiental e educação física: uma construção sustentável possível. Simpósio Nacional sobre Geografia, Percepção e Cognição do Meio Ambiente, 2005; Londrina.

8. Bento LCM, Ribeiro RD. Educação física e meio 
ambiente: Nas trilhas do Eco Turismo um estudo de caso do município de Indianópolis, MG. Em Extensão. 2010; 9(1):183-194.

9. Mello AS. Lazer e educação ambiental: relato de Experiências na formação inicial em Educação Física. Licere. 2013;16(2):1-13.

10. Marinho A. Natureza, tecnologia e esportes: novos rumos. Conexões. 1999;1(2):60-9.

11. Betrán JO. Las actividades físicas de aventura em La natureleza: análise sociocultural. In: Apunts, Educación Física y Desportos. Barcelona. 1995; (41):5-8.

12. Tahara AK, Schwartz GM. Atividades de aventura na natureza: investindo na qualidade de vida. Lecturas. 2003;8(58). Disponível em www.efdeportes.com. Acesso em: 14 de fevereiro 2015.

13. Bruhns HT. Lazer e meio ambiente: corpos buscando o verde e a aventura. Rev Bras Ciênc Esporte. 1997;18(2):86-91.

14. Martelli M, Cardoso MM, Barbosa Junior J. Analise de uma ação ambiental visando arborização urbana realizada no interior de uma escola estadual no município de Itapira-SP. Eduambiental. 2013;3(1):14-25.

15. Silva AM. A dominação da natureza: o intento do ser humano. Rev Bras Ciênc Esporte. 1997;18(2):11925.

16. Domingues SC, Kunz L, Araújo LCGD. Educação ambiental e Educação física. Possibilidades para formação de professores. Rev Bras Ciênc Esporte. 2011;33(3):559-71.

17. Pinto LR, Corrêa LR. Arborização de vias públicas de Inconfidentes, MG, empregando a educação ambiental. In: Anais do I Congresso Brasileiro de Gestão Ambiental, 2010; Bauru. Bauru: IBEAS Instituto Brasileiro de Estudos Ambientais; 2010. p.1-5.

18. Dantas DS, Souza IC. Arborização urbana na cidade de Campina Grande - PB: inventario e suas espécies, Bioterra. 2004;4(2). Disponível em http://joaootavio.com.br/bioterra/workspace/uploads/ artigos/arborizaurbana-515646a391755.pdf. Acesso em: 14 de fevereiro 2015.

19. Raber AP, Rebelato GS. Arborização viária do município de colorado, RS - Brasil: análise qualiquantitativa. REVSBAU. 2010;5(1):183-99.

20. Pinheiro CSC, Terra C, Avero CS. Plantio de amoreira (Morus negra L.) para arborização de espaço físico escolar como proposta de educação física. Capa. 2009;1(1).

21. Rezende TD, Santos D. Avaliação qualitativa de arborização das praças do bairro Jaraguá, Uberlândia - MG. REVSBAU. 2010;5(2):139-57.

22. Prefeitura de Mogi Guaçu. Disponível em: $<$ http://www.mogiguacu.sp.gov.br/v2/vnoticias.php?i dnoticia $=00000002558>$ Acesso em: 14 de fevereiro 2015.

23. Prefeitura de Mogi Guaçu. Disponível em: <http://www.mogiguacu.sp.gov.br/v2/cidade.php> Acesso em: 28 de fevereiro 2015.

24. Martelli M, Giovelli FA, Arruda MPD, Cardoso MM. Projeto Parceiros do Verde e a Educação Ambiental na Reconstituição de uma Área Ciliar do Município de Itapira - SP. Eduambiental. 2012;2(1):92-104.

25. Ribeiro FABS. Arborização urbana em Uberlândia: percepção da população Revista da Católica. 2009;1(1):224-37.

26. Ferreira ES, Amador MBM. Arborização Urbana: A questão das praças e calçadas no município de Lajedo-PE e a percepção da população. IX Fórum Ambiental da Alta Paulista. 2013;9(4):59-78.

27. Santos ES. Reflexões sobre a utilização de espaços públicos para o lazer esportivo. RA'E GA. 2006;(11):25-33.

28. Muniz AC, Almeida AC, Barbosa G, Santos S, Cardoso LF, Sanchez S. Arborização escolar: a pratica da educação agroecológica. Mostra nacional de iniciação cientifica e tecnológico interdisciplinar. Mostra Nacional de Iniciação Científica e Tecnológica Interdisciplinar - VI MICTI, Instituto Federal Catarinense - Campus Camboriú, 2013.

29. Oliveira AS, Sanches L, Musis CR, Nogueira MCJA. Benefícios da arborização em praças urbanas - O caso de Cuiabá - MT, Rev Elet Gestão, Educação e Tecnologia Ambiental. 2013;9(9):1900-15.

\section{CONFLITO DE INTERESSES}

Os autores declaram não haver conflitos de interesse.

\section{AUTOR PARA CORRESPONDÊNCIA}

Anderson Martelli

martellibio@hotmail.com

Submetido em 25/07/2016 Aceito em 09/08/2016 